\title{
Clinical predictors of pulmonary hypertension in sarcoidosis
}

\author{
J.M. Bourbonnais and L. Samavati
}

ABSTRACT: Pulmonary hypertension (PH) adversely affects outcome in sarcoidosis and is an important predictor of mortality in these patients. Early and accurate diagnosis of this complication may improve outcome. The current authors hypothesised that integration of 6-min walk test (6MWT) as part of the evaluation leads to an earlier diagnosis of this complication.

A total of 162 patients with sarcoidosis underwent 6MWT. Demographic and pulmonary function results were analysed. Patients were further assessed by echocardiography and right heart catheterisation when clinically indicated.

Patients with sarcoidosis-associated PH had significantly decreased results on pulmonary function testing. They also walked shorter distances and desaturated to lower levels on 6MWT. On logistic regression analyses, significant predictors of $\mathrm{PH}$ were oxygen saturation $<\mathbf{9 0} \%$ on $\mathbf{6 M W T}$ (odds ratio (OR) 12.1, 95\% confidence interval $(\mathrm{Cl}) 3.66-19.73$ ) and diffusing capacity of the lung for carbon monoxide $<60 \%$ predicted (OR 7.3, 95\% Cl 1.98-24.82). Moreover, by combining the results of oxygen saturation at $6 \mathrm{~min}$ with those of echocardiography, the ability to correctly predict the presence of $\mathrm{PH}$ by right heart catheterisation was improved.

Patients with diffusing capacity of the lung for carbon monoxide $<60 \%$ predicted and oxygen desaturation $<\mathbf{9 0} \%$ on 6 -min walk test have a high likelihood of pulmonary hypertension and should undergo further evaluation for the presence of this disorder.

KEYWORDS: Pulmonary fibrosis, pulmonary hypertension, sarcoidosis, 6-min walk distance

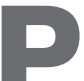

ulmonary hypertension $(\mathrm{PH})$ is one potential complication of sarcoidosis that causes significant morbidity and mortality $[1,2]$. The epidemiology of sarcoidosis-associated $\mathrm{PH}$ is not well studied. The frequency has been reported from 1 to $50 \%$, but may be as high as $75 \%$ in patients awaiting lung transplantation [17]. The diagnosis is difficult and a high index of suspicion is necessary owing to variability in presentation and nonspecific symptoms [8]. Most patients experience gradually worsening symptoms of dyspnoea, syncope and heart failure, but a small number die unexpectedly [8]. Since PH is an important predictor of mortality in patients awaiting lung transplantation, noting its presence may prompt earlier referral to a transplant centre or introduction of therapy that may improve outcomes $[5,7,9]$.

The severity of PH may not correlate well with the degree of pulmonary fibrosis, pulmonary function test (PFT) values, or blood gas tensions $[1,2,4]$. One potential marker for $\mathrm{PH}$ is reduced 6-min walk test (6MWT) performance. The 6MWT assesses complex physiological interactions, including pulmonary, cardiovascular and neuromuscular systems [10]. The 6-min walk distance (6MWD) is widely used for the purpose of repeated measures of exercise capacity and to assess the effectiveness of therapeutic interventions in a variety of conditions [11-13]. It may also better reflect the level of functional capacity required for daily physical activities than cardiopulmonary exercise testing [14, 15]. A short 6MWD predicts, fairly accurately, morbidity and mortality from most heart and lung diseases [1621]. However, the degree of desaturation during 6MWT may be a stronger predictor of mortality in some conditions, such as idiopathic pulmonary fibrosis (IPF) and primary $\mathrm{PH}$ [21-23].

The use of the 6MWT in patients with sarcoidosis has not been well established. Because of its simplicity and ability to predict outcome, the current authors hypothesised that the 6MWT would be useful as a screening tool for sarcoidosisassociated PH. It was also proposed that desaturation would be more predictive of the presence of $\mathrm{PH}$ than distance walked. To test these hypotheses, all patients were first evaluated with the 6MWT and PFT. A total of 141 patients underwent two-dimensional Doppler echocardiography (2D echo) and 35 underwent right heart catheterisation (RHC) for further evaluation.
AFFILIATIONS

Dept of Medicine, Division of

Pulmonary, Allergy, Critical Care and Sleep Medicine, Wayne State University School of Medicine Detroit Medical Center, Detroit, MI, USA.

CORRESPONDENCE

L. Samavati

Division of Pulmonary Allergy

Critical Care and Sleep

Wayne State University School of

Medicine

3990 John $\mathrm{R}$

3 Hudson

Detroit

MI 48201

USA

Fax: 13139330562

E-mail: Isamavat@med.wayne.edu

Received:

December 272007

Accepted after revision:

March 112008

STATEMENT OF INTEREST

None declared.

Online ISSN 1399-3003 


\section{METHODS AND MATERIALS}

\section{Study design}

The Sarcoidosis and Interstitial Lung Disease Center at Wayne State University-Detroit Medical Center in Detroit, MI, USA is a referral centre for patients with sarcoidosis and other interstitial lung diseases. The medical records of 162 patients who underwent 6MWT were prospectively reviewed and data regarding demographics, radiography, PFT and cardiac evaluation were recorded. Approval for the use of these data was obtained from the Institutional Review Board of Wayne State University.

\section{Methods}

Sarcoidosis was diagnosed in all patients as per standard guidelines [24]. Chest radiography was interpreted as stage 0-4 [24]. PFTs were performed in 160 patients following American Thoracic Society guidelines in a licensed laboratory [25, 26]. All spirometry studies were performed using a calibrated pneumotachograph and lung volumes were measured in a whole-body plethysmograph (Jaeger Spirometry and SensorMedics Vmax 22; VIASYS Respiratory Care, Inc., Yorba Linda, CA, USA).

All patients completed at least one 6MWT, performed by a licensed respiratory therapist following standardised protocol [10]. Oxygen saturation was measured using a finger probe pulse oximeter (NPB-40; Nellcor, Pleasanton, CA, USA). All subjects demonstrated a resting saturation of $>88 \%$ at initiation of testing. Variables used for analysis included Borg dyspnoea score, 6MWD and oxygen saturation. The $6 \mathrm{MWD} \%$ predicted was calculated based on a formula that incorporates body mass index (BMI) and age [27]. A total of 141 patients underwent further evaluation with $2 \mathrm{D}$ echo and 35 patients had RHC. With echocardiography, $\mathrm{PH}$ was defined as a right ventricle systolic pressure $>40 \mathrm{mmHg}$ in the absence of significant left heart dysfunction, based on the criteria established by the World Health Organization Symposium on Primary Pulmonary Hypertension [9, 28, 29]. RHC was performed to confirm the diagnosis in patients who had evidence of $\mathrm{PH}$ on 2D echo and in patients with inconclusive echocardiography, in the presence of repeatedly abnormal $6 \mathrm{MWT}$ and despite optimisation of therapy.

\section{Analysis}

Continuous data are presented as mean $\pm \mathrm{SD}$. Categorical data are presented as frequency and percentage. Analysis of variance and independent unpaired t-tests were used for analyses of continuous variables and the Chi-squared test for assessing the discrete variables. Bivariate Spearman's rank correlation coefficient was calculated to measure the relationship between the clinical variables and $\mathrm{PH}$. The diagnostic value of the model was assessed by constructing receiver operating characteristic (ROC) curves using different independent variables against the presence of PH. The sensitivity, specificity, positive predictive value and negative predictive value were calculated using the area under the curve (AUC). Multivariate logistic regression analyses were performed for the dependent variables of presence or absence of $\mathrm{PH}$, to identify independent factors predicting $\mathrm{PH}$ and to generate odds ratios (ORs). For all analyses, two-tailed p-values $<0.05$ were considered significant.

\section{RESULTS}

The study group was made up of 162 patients. Patient demographics appear in table 1 . The mean age was $47 \pm 12$ yrs. Approximately $77 \%$ of subjects were female and $88 \%$ were African-American. The mean BMI was $33 \pm 8.9 \mathrm{~kg} \cdot \mathrm{m}^{-2}$. The majority of subjects had chest radiography scores $<3$. Approximately $67 \%$ of patients had active disease and the majority were receiving treatment with either steroids, immunomodulatory drugs or both. Nonsmokers comprised $85.8 \%$ of patients and smokers $14.2 \%$. In total, 141 patients had echocardiographic assessment for $\mathrm{PH}$ and 35 patients underwent both echocardiography and catheterisation diagnostic assessments. In comparison to the results of RHC, seven patients were found to have false-negative 2D echo studies. Three patients had elevated pulmonary artery pressure in the presence of elevated pulmonary capillary wedge pressure and, based on the World Health Organization criteria, were considered false positives.

Variables used in analyses, characterised by findings on RHC, are listed in table 2. Patients with $\mathrm{PH}$ demonstrated on $\mathrm{RHC}$ were compared with all other patients. The results demonstrate that patients with definitive sarcoidosis-associated $\mathrm{PH}$ by RHC are significantly different from those without PH. On analysis of PFT results, significant differences were noted in all parameters. The \% predicted values for forced vital capacity (FVC), forced expiratory volume in one second (FEV1) and

\begin{tabular}{|c|c|}
\hline Age yrs & $47 \pm 12$ \\
\hline BMI $\mathbf{k g} \cdot \mathrm{m}^{-2}$ & $33 \pm 8.9$ \\
\hline \multicolumn{2}{|l|}{ Sex } \\
\hline Male & $38(23.5)$ \\
\hline Female & $124(76.5)$ \\
\hline \multicolumn{2}{|l|}{ Race } \\
\hline African-American & $143(88.3)$ \\
\hline White & $19(11.7)$ \\
\hline \multicolumn{2}{|c|}{ Chest radiograph stage } \\
\hline 0 & $32(19.8)$ \\
\hline 1 & $28(17.3)$ \\
\hline 2 & $53(32.7)$ \\
\hline 3 & $15(9.3)$ \\
\hline 4 & $31(19.1)$ \\
\hline \multicolumn{2}{|l|}{ Disease } \\
\hline Inactive & $54(33.3)$ \\
\hline Active $^{\#}$ & $108(66.7)$ \\
\hline Disease duration yrs & $1-35$ \\
\hline \multicolumn{2}{|l|}{ Medication } \\
\hline None & $57(35.2)$ \\
\hline Steroidal & $24(14.8)$ \\
\hline IMD & $33(20.4)$ \\
\hline Steroidal and IMD & $48(29.6)$ \\
\hline \multicolumn{2}{|l|}{ Smoking status } \\
\hline Nonsmoker & $139(85.8)$ \\
\hline Smoker & $23(14.2)$ \\
\hline
\end{tabular}

Data are presented as mean $\pm \mathrm{SD}, \mathrm{n}(\%)$ or range. BMI: body mass index; IMD immune modifying drug. ${ }^{\#}$ : defined as requirement for steroids in previous 6 months $\because$ e.g. methotrexate, azathioprine and others. 


\begin{tabular}{|c|c|c|c|c|c|}
\hline $\begin{aligned} & \text { TABLE } 2 \text { Cha } \\
& \text { hyp } \\
& \text { catl } \\
& \text { pat }\end{aligned}$ & $\begin{array}{l}\text { aracteristi } \\
\text { ertension } \\
\text { heter com } \\
\text { ients }\end{array}$ & $\begin{array}{l}\text { s of patie } \\
\text { (PH) diag } \\
\text { pared with }\end{array}$ & $\begin{array}{l}\text { ts with pi } \\
\text { osed by } \\
\text { all other }\end{array}$ & $\begin{array}{l}\text { ulmonary } \\
\text { right heart } \\
\text { sarcoidos }\end{array}$ & \\
\hline \multirow[t]{2}{*}{ Variables } & \multicolumn{2}{|c|}{ Present } & \multicolumn{2}{|c|}{ All others } & \multirow[t]{2}{*}{ p-value } \\
\hline & $\begin{array}{c}\text { Subjects } \\
n\end{array}$ & Mean \pm SD & $\begin{array}{c}\text { Subjects } \\
n\end{array}$ & Mean \pm SD & \\
\hline FVC \% pred & 22 & $55 \pm 19$ & 139 & $79 \pm 18$ & $<0.001$ \\
\hline FEV $_{1} \%$ pred & 22 & $52 \pm 18$ & 139 & $80 \pm 20$ & $<0.001$ \\
\hline TLC \% pred & 22 & $68 \pm 18$ & 137 & $85 \pm 18$ & $<0.001$ \\
\hline DL,CO \% pred & 22 & $42 \pm 18$ & 138 & $70 \pm 21$ & $<0.001$ \\
\hline 6MWD \% pred & 22 & $64 \pm 18$ & 140 & $79 \pm 19$ & 0.001 \\
\hline 6MWD m & 22 & $343 \pm 116$ & 140 & $426 \pm 105$ & 0.004 \\
\hline $\begin{array}{l}\mathrm{O}_{2} \text { saturation at } \\
1 \mathrm{~min} \%\end{array}$ & 22 & $96 \pm 2$ & 140 & $98 \pm 2$ & 0.005 \\
\hline $\begin{array}{l}\mathrm{O}_{2} \text { saturation at } \\
6 \mathrm{~min} \%\end{array}$ & 22 & $88 \pm 4$ & 140 & $95 \pm 4$ & $<0.001$ \\
\hline $\mathrm{O}_{2}$ desaturation $\%$ & 22 & $8.85 \pm 4.22$ & 140 & $2.99 \pm 2.14$ & $<0.001$ \\
\hline Borg at $1 \mathrm{~min}$ & 22 & $2.08 \pm 1.54$ & 140 & $1.49 \pm 1.52$ & 0.109 \\
\hline Borg at $6 \mathrm{~min}$ & 22 & $6.00 \pm 2.55$ & 140 & $4.07 \pm 2.23$ & $<0.001$ \\
\hline $\begin{array}{l}\text { Chest radiograph } \\
\text { stage }\end{array}$ & 22 & $3 \pm 1.2$ & 137 & $1.6 \pm 1.3$ & $<0.001$ \\
\hline
\end{tabular}

Variables were included to explain the differences between the PH confirmed cases by right heart catheter and those with undetermined or absence of $\mathrm{PH}$. pvalues were determined using unpaired t-test. FVC: forced vital capacity; \% pred: \% predicted; FEV1: forced expiratory volume in one second; TLC: total lung capacity; $D L, C O$ : diffusing capacity of the lung for carbon monoxide; 6MWD: 6-min walk distance.

total lung capacity (TLC) were lower in patients with definitive evidence of $\mathrm{PH}(\mathrm{p}<0.001$ for each). The diffusion level of the lung for carbon monoxide (DL,CO) \% pred is significantly reduced in patients with sarcoidosis-associated $\mathrm{PH}$ compared with patients without $\mathrm{PH}(\mathrm{p}<0.001)$. Further assessment of the effect of smoking as a confounding factor on $D \mathrm{~L}, \mathrm{CO} \%$ pred in the presence of $\mathrm{PH}$ did not attain significance $(p=0.1)$. Both $6 \mathrm{MWD}$ and oxygen desaturation during 6MWT were significantly lower in patients with $\mathrm{PH}$. Although the Borg dyspnoea score at $1 \mathrm{~min}$ did not reach statistical significance, the 6-min scores were significantly different between the two groups $(\mathrm{p}<0.001)$. Patients with PH walked an average of $343 \pm 116 \mathrm{~m}$ compared with $426 \pm 105 \mathrm{~m}$ for all other patients $(p=0.004)$. Those with documented $\mathrm{PH}$ also desaturated significantly more from initiation to completion of 6MWT: $8.9 \pm 4.22$ versus $2.99 \pm 2.14 \%$, respectively $(\mathrm{p}<0.001)$.

Similar results were obtained when the presence of $\mathrm{PH}$ was used as the dependent variable and compared with groups with absent $\mathrm{PH}$ on 2D echo. Those with echocardiographic evidence of $\mathrm{PH}$ also had significantly greater desaturation at 6 min than those without $\mathrm{PH}(\mathrm{p}<0.001)$, as seen in figure 1 . Chest radiography scores were higher in patients with $\mathrm{PH}$ than in the cohort group without $\mathrm{PH}(\mathrm{p}<0.001)$. Patients with $\mathrm{PH}$ also had significantly lower $D L, C O \%$ pred values $(p<0.001)$. The relationship between the degree of oxygen desaturation and DL,CO was further explored. A scatter plot of DL,CO \%

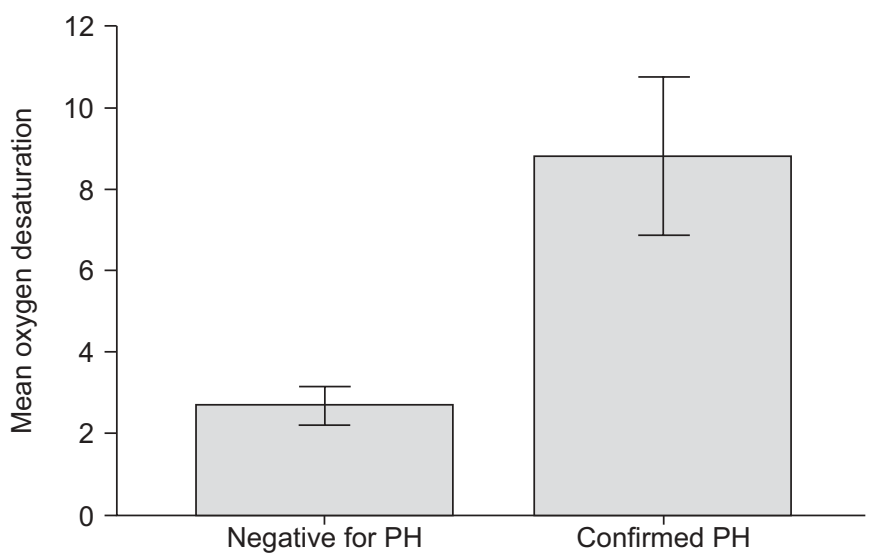

FIGURE 1. Quantitative relationship between oxygen desaturation during 6min walk test and evaluation of patients for pulmonary hypertension $(\mathrm{PH})$. Mean $\pm \mathrm{SD}$ of desaturation of two groups of patients evaluated by two-dimensional Doppler echocardiography were compared: those with confirmed $\mathrm{PH}$ and those negative for $\mathrm{PH}$. A significant difference was observed between patients who showed presence of $\mathrm{PH}$ and patients with negative echocardiography $(\mathrm{p}<0.001)$.

pred versus oxygen saturation at completion of a $6 \mathrm{MWT}$ is shown in figure 2. A correlation of $r=0.58$ was found between these two variables. When the change in saturation was substituted for the absolute level of saturation a correlation of $r=0.54$ was found. A lower correlation of $r=0.22$ was found between predicted 6MWD and oxygen saturation at completion of 6MWT (data not shown).

Multiple ROC curves were constructed to evaluate the diagnostic accuracy of the oxygen saturation level at $6 \mathrm{~min}$, $D \mathrm{~L}, \mathrm{CO} \%$ pred and $6 \mathrm{MWD}$ to predict the presence of $\mathrm{PH}$ on $2 \mathrm{D}$ echo and RHC. The ROC curves to predict the presence of $\mathrm{PH}$ by $2 \mathrm{D}$ echo demonstrated an AUC of 0.88 (95\% confidence interval (CI) 0.82-0.95) for DL,CO \% pred $(\mathrm{p}<0.001)$; AUC 0.93 (95\% CI $0.89-0.98)$ for oxygen saturation at $6 \mathrm{~min}(\mathrm{p}<0.001)$; and AUC $0.61(95 \%$ CI $0.575-0.79)$ for $6 \mathrm{MWD}(\mathrm{p}=0.05$; figures not shown). Figure 3 and table 3 demonstrate the ROC curves generated using these same variables and substituting RHC (the gold standard) for 2D echo to predict the presence of $\mathrm{PH}$. The only two that demonstrated robust AUC values were again the oxygen saturation at $6 \mathrm{~min}$ (AUC 0.92, 95\% CI 0.80 $0.98 ; \mathrm{p}<0.001$ ) and DL,CO \% pred (AUC 0.74, 95\% CI 0.54-0.97; $\mathrm{p}=0.02$ ). Both $6 \mathrm{MWD}$ and $6 \mathrm{MWD} \%$ pred did not reach statistical significance (AUC 0.55, 95\% CI 0.36-0.74; $\mathrm{p}=0.64$; and AUC 0.57, 95\% CI 0.4-0.79; $\mathrm{p}=0.331$ ). These results clearly demonstrate that the level of oxygen saturation at $6 \mathrm{~min}$ is by far statistically superior to the 6MWD and DL,CO \% pred in predicting the presence of $\mathrm{PH}$ in patients with sarcoidosis.

Multivariate logistic regression analyses were performed using the different composite models and adjusting for BMI and age. The only two variables that remained significant were oxygen saturation at 6 min with OR 0.688 (95\% CI 0.55-0.86) for each unit change in saturation $(\mathrm{p}<0.001)$ and $D \mathrm{~L}, \mathrm{CO} \%$ pred $(\mathrm{OR}$ $0.95,95 \%$ CI $0.9-1.0 ; p=0.04)$. Using the cut-off values obtained from the ROC curve for oxygen saturation at $6 \mathrm{~min}$, patients were categorised into two groups: one whose oxygen saturation remained $>90 \%$ and another whose oxygen saturation dropped $<90 \%$. Patients were also categorised into two groups 


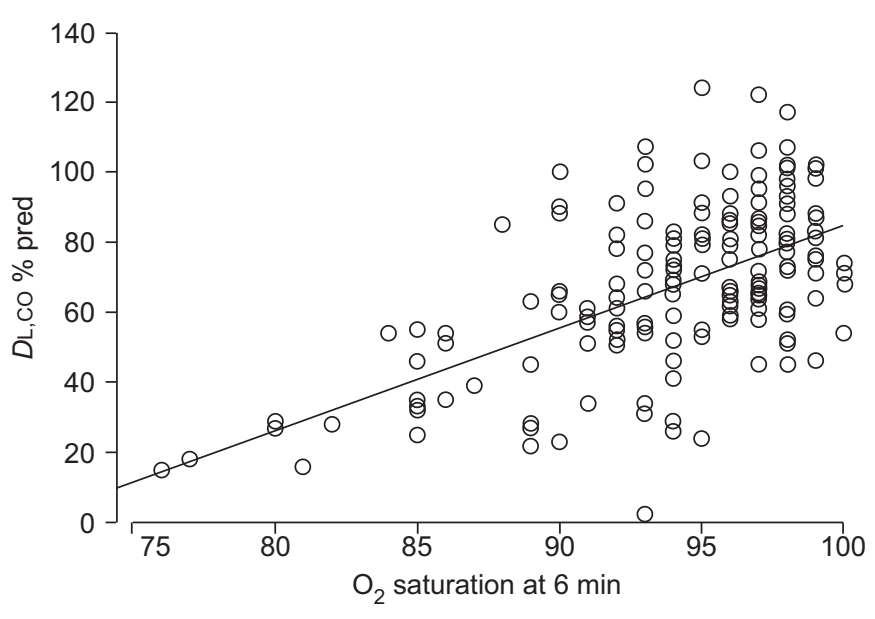

FIGURE 2. Scatter plot showing the correlation of diffusing capacity of the lung for carbon monoxide $(D L, C O) \%$ predicted and oxygen saturation after 6-min walk test. Linear curves were fitted and the best fits were found to explain $58 \%$ of correlation between $D \mathrm{~L}, \mathrm{CO} \%$ pred and oxygen saturation at $6 \mathrm{~min}(r=0.58)$.

based on DL,CO \% pred: one with DL,CO \% pred $>60 \%$ and the other below this benchmark. Using these defined groups, logistic regression analyses were carried out in order to predict the probability of $\mathrm{PH}$ occurring on 2D echo among these categories. After adjusting for BMI and age, the OR for patients with oxygen saturation $<90 \%$ was 12.1 (95\% CI $3.66-19.73$; $\mathrm{p}<0.001)$. Patients with a DL,CO $\%$ pred $<60 \%$ had OR $7.3(95 \%$ CI 1.98-24.82; $\mathrm{p}=0.03)$. The other variables tested, including 6MWD, 6MWD \% pred and all other PFT values did not attain statistical significance in predicting the presence of $\mathrm{PH}$. Most importantly, logistic regression analyses were performed in order to predict the established diagnosis of PH via RHC using several composite models. The very best model to predict the presence of $\mathrm{PH}$ as determined by $\mathrm{RHC}$, after adjusting for age and BMI, was oxygen saturation after 6MWT (OR 0.58, 95\% CI $1.22-1.58 ; \mathrm{p}=0.031)$. DL,CO \% pred did not attain significance in this model. The ability of this model to accurately predict the presence of $\mathrm{PH}$ as determined by $\mathrm{RHC}$, the gold standard, was superior to using the $2 \mathrm{D}$ echo alone.

\section{DISCUSSION}

In the present study, the characteristics of patients with sarcoidosis-associated $\mathrm{PH}$ were evaluated against those without evidence of $\mathrm{PH}$ in an attempt to identify specific variables that would suggest the presence of this complication. To the current authors' knowledge, this is the largest series of patients evaluated with complete physiological data for this purpose, including 35 patients with RHC. Previous studies have failed to identify any consistent simple clinical criteria to be used as a guide to determine who requires further evaluation. The present data indicate that patients with sarcoidosis-associated $\mathrm{PH}$ desaturate to $<90 \%$ during $6 \mathrm{MWT}$.

No demographic variables were related to the presence of $\mathrm{PH}$ in the present study. The population consists almost entirely of African-American females and it would have been difficult to note any statistical trends, but this finding is in agreement with a retrospective review of patients awaiting transplantation [30]. The results also corroborate the findings of others that patients with $\mathrm{PH}$ are more likely to have advanced radiographic stage disease $[2,4]$. However, three patients with relatively wellpreserved lung function and radiological stage 2 disease were found to have PH by RHC. All three patients presented with hypoxia on 6MWT, yet two had negative echocardiography.

Both 6MWD and desaturation during 6MWT seem to correlate with mortality in a variety of diseases, but it is unclear whether distance or the oxygen saturation nadir provide more accurate prognostic information. In several disorders, 6MWD has been shown to be independently related to mortality, and a lesser distance walked is associated with a poorer prognosis [16-20]. Previous studies have identified walking $<300 \mathrm{~m}$ as a prognostic marker of cardiac death and $<400 \mathrm{~m}$ as a reasonable marker for when a patient should be listed for lung transplantation $[16,19]$. The present patients with $\mathrm{PH}$ walked an average of $\sim 350 \mathrm{~m}$ and displayed significantly higher Borg dyspnoea scores than those without $\mathrm{PH}$, corroborating recent findings that patients with sarcoidosis-associated $\mathrm{PH}$ have shorter 6MWD [6]. However, many factors may affect 6MWD, including certain patient characteristics and effort. The results suggest that, in patients with sarcoidosis, the degree of desaturation provides more valuable prognostic information than the 6MWD.

The ability of several variables to predict the presence of $\mathrm{PH}$ was assessed with ROC curves. The performance characteristics of 6MWD were poor (AUC 0.55) in comparison to the level of oxygen saturation at 6 min (AUC 0.92). The current study demonstrates a clear correlation between greater degrees of desaturation and the presence of $\mathrm{PH}$ in sarcoidosis. Some previous studies have suggested that the degree of desaturation during $6 \mathrm{MWT}$ is a strong predictor of mortality in IPF and primary $\mathrm{PH}$, with oxygen desaturation to $\leqslant 88 \%$ at the end of $6 \mathrm{MWT}$ associated with a higher mortality $[18,20,22,23]$. In the present study, logistic regression analyses indicated that the highest degree of both sensitivity and specificity was achieved with a cut-off of $90 \%$ saturation at 6 min. Patients with a saturation $<90 \%$ during a $6 \mathrm{MWT}$ were $\sim 12$ times more likely to have PH. Although the study did not assess mortality, four patients with $\mathrm{PH}$ died due to sudden cardiac events during follow-up, whereas no others have expired. All had poor performance on $6 \mathrm{MWT}$ with oxygen saturation levels of $<90 \%$ at completion.

PFT values have been shown to be unreliable in screening for $\mathrm{PH}$, secondary to discrepancies between studies. Some studies have shown statistically lower FVC, FEV1 and TLC values in patients with $\mathrm{PH}$, while others have shown higher values or no difference between groups $[1,2,4,7,30]$. The present results showed that patients with $\mathrm{PH}$ had decreases in all PFT values (FEV1, FVC and TLC), but none of these variables retained significance when controlled for age and BMI on multivariate logistic regression analyses. Patients with evidence of $\mathrm{PH}$ did have significantly lower levels of $D \mathrm{~L}, \mathrm{CO}$, and levels $<60 \%$ were independently associated with $\mathrm{PH}$ on logistic regression analyses with an OR of 7.3. These findings are in agreement with other studies that have shown statistically significant differences in $\mathrm{DL}, \mathrm{CO}$ among patients with $\mathrm{PH}$, even in the absence of fibrosis on chest radiography [1, 4, 5]. The present data also highlight a good correlation between the oxygen saturation level at $6 \mathrm{~min}$ and $\mathrm{DL}, \mathrm{CO} \%$ pred $(\mathrm{r}=0.58)$, and both 

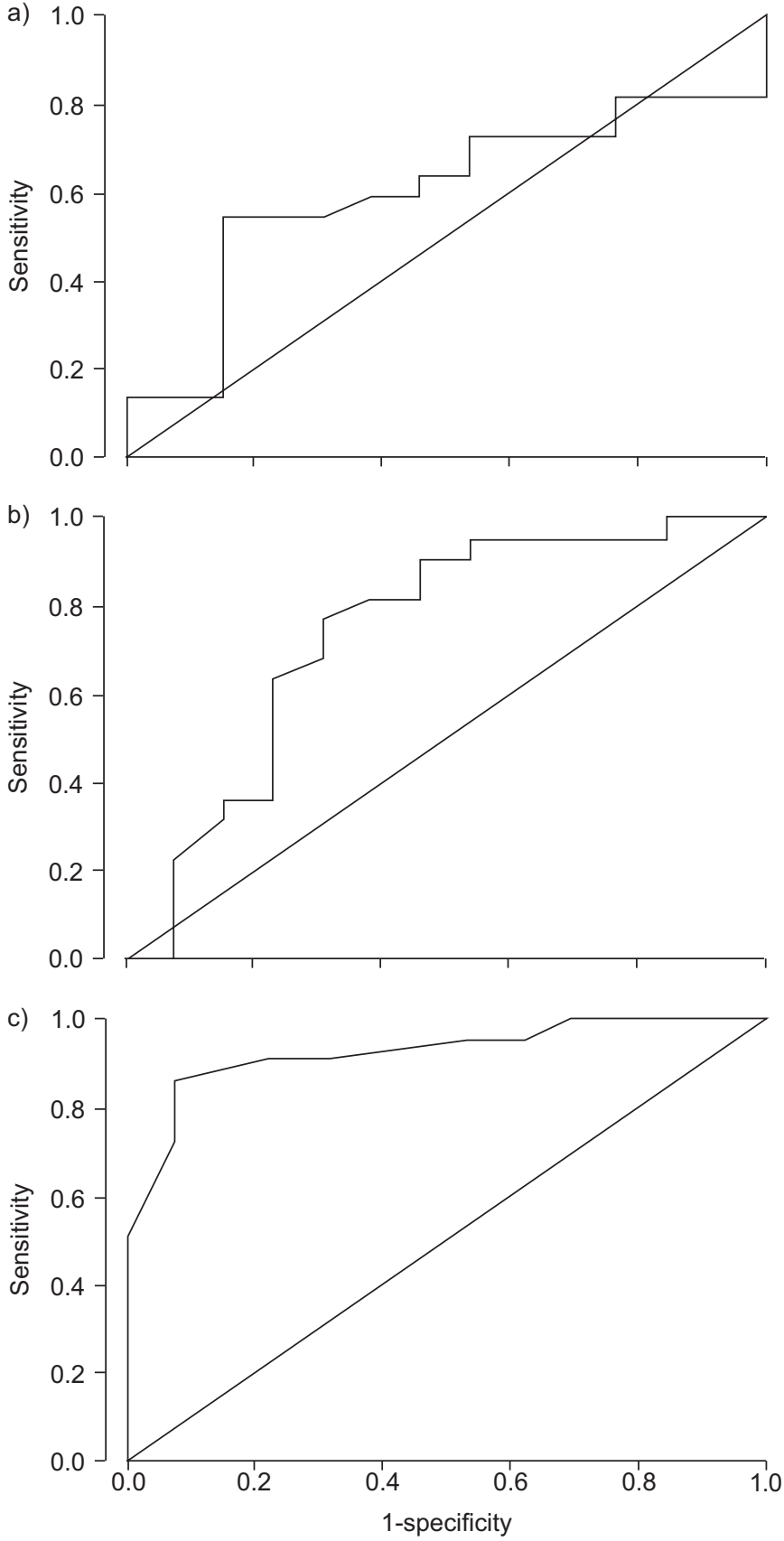

FIGURE 3. Receiver operating characteristic curves for a) 6-min walk distance $(6 \mathrm{MWD}) \%$ predicted, b) diffusing capacity of the lung for carbon monoxide $(D\llcorner, \mathrm{CO})$ $\%$ pred and c) oxygen saturation at 6 min versus presence of pulmonary hypertension as determined by right heart catheterisation. The area under the curve (AUC) for 6MWD \% pred was 0.57 (95\% confidence interval $(\mathrm{Cl})$ 0.4-0.8; $\mathrm{p}=0.33$ ); $\mathrm{A} \cup \mathrm{C}$ for $\mathrm{D} \mathrm{L}, \mathrm{CO} \%$ pred was 0.74 (95\% Cl 0.55-0.93; $\mathrm{p}=0.018$ ); and for oxygen saturation at $6 \mathrm{~min}$ was $0.916(95 \% \mathrm{Cl} 0.88-0.99 ; \mathrm{p}<0.001)$. See also table 3 .

variables were independently associated with the presence of $\mathrm{PH}$. Interestingly, only $5.5 \%$ of study patients were on longterm oxygen therapy. This proportion increased to $40 \%$ among patients with $\mathrm{PH}$. Although the current authors believe that the aetiology of sarcoidosis-associated $\mathrm{PH}$ is multifactorial, these

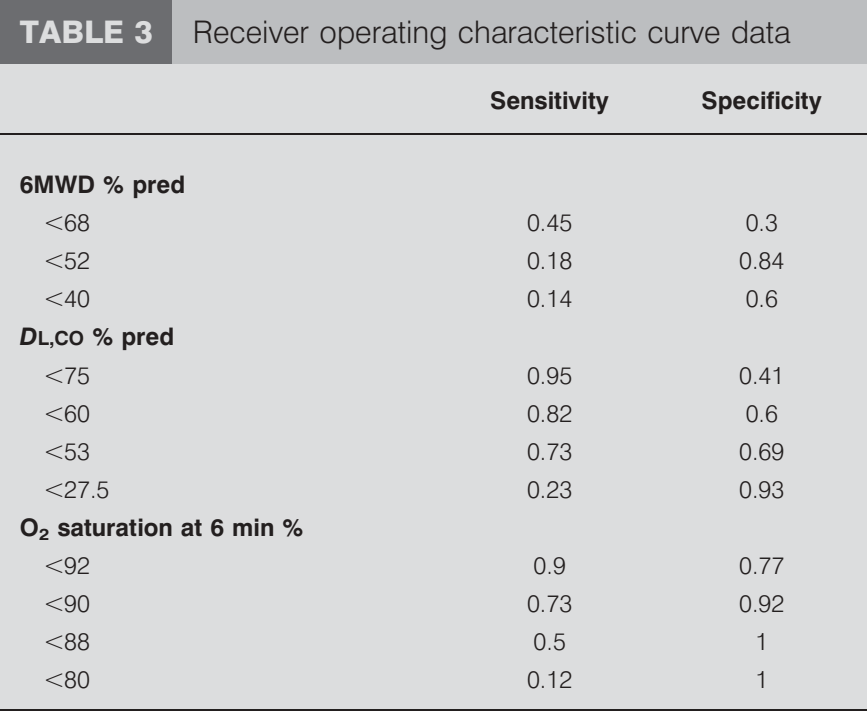

Data are presented for 6-min walk distance $(6 \mathrm{MWD}) \%$ predicted, diffusing capacity of the lung for carbon monoxide $(D \mathrm{~L}, \mathrm{CO}) \%$ pred and oxygen saturation at 6 min versus presence of pulmonary hypertension as determined by right heart catheterisation. Receiver operating characteristic curves from which these data were obtained are shown in figure 3 .

findings suggest that parenchymal destruction and hypoxia account, in part, for the observed $\mathrm{PH}$ in these patients.

Although several studies have demonstrated a strong correlation between pulmonary artery pressure as measured by echocardiography and pressures as measured by RHC, others have shown that Doppler values markedly underestimate pulmonary artery pressure [28, 29]. In the current study, reliance solely on echocardiography to determine the presence of $\mathrm{PH}$ would have led to seven cases being misdiagnosed as having no $\mathrm{PH}$ (32\% of those with $\mathrm{PH})$. All seven patients had $D$ L,CO $\%$ pred $<60 \%$ and desaturated to $<90 \%$ during $6 \mathrm{MWT}$. The results suggest that using a composite model of saturation during 6MWT will increase the pre-test probability, even if the 2-D echo is negative, before performing RHC in patients with a high clinical suspicion of $\mathrm{PH}$.

The present study represents the most complete set of data for this category of patients. Although the study by SulICA et al. [4] presented 106 patients with echocardiography, only three patients had RHC confirming PH. In the study by HANDA et al. [2], all 246 patients followed in their sarcoidosis clinic underwent echocardiography; however, the purpose of that study was to establish the frequency of $\mathrm{PH}$ in an outpatient sarcoidosis population. The present study was not designed to establish the frequency of sarcoidosis-associated $\mathrm{PH}$, but to identify high-risk patients and to assess relevant clinical characteristics that are suggestive of the presence of this complication. The frequency of $\mathrm{PH}$ in the present population was $14 \%$. This may be an overestimation, since the current authors' clinic is a tertiary referral centre and may follow more advanced diseases. Another limitation of the current study is that the population consists almost entirely of AfricanAmerican females. Since the disease pattern appears different in black subjects compared with white subjects, the results may 
overestimate the incidence of $\mathrm{PH}$ in this condition. The present study may appear to have some degree of selection bias owing to the fact that RHC studies were performed in subjects with desaturation on 6MWT and negative or inconclusive echocardiography results. However, it would be impractical to conduct RHC in all patients without any clinical suspicion of $\mathrm{PH}$ and negative 2D echo.

There is a need for the development of an early detection method for $\mathrm{PH}$ in sarcoidosis and other fibrotic lung disease. This will require the identification and validation of noninvasive measures that can predict this complication [28]. The present authors' study strongly suggests that all patients with sarcoidosis should undergo a 6MWT. If they show oxygen desaturation during this test, they should be evaluated for $\mathrm{PH}$ as well as home oxygen. Since the diagnostic accuracy of 2D echo has a relatively low sensitivity, these additional variables can help determine who should undergo further evaluation by RHC. The integration of these simple parameters into evaluation of sarcoidosis may lead to an earlier and more accurate diagnosis of $\mathrm{PH}$ in this patient population. Although it is unclear whether long-term treatment with currently available medications will improve morbidity or mortality in this category of patients, this may lead to early detection and assist in designing a prospective, longitudinal study.

In conclusion, patients with sarcoidosis-associated pulmonary hypertension are significantly different in multiple areas. Most patients with pulmonary hypertension have advanced stages of sarcoidosis on chest radiography, and poor performance on pulmonary function testing and 6-min walk test. Diffusing capacity of the lung for carbon monoxide levels $<60 \%$ predicted and desaturation to $<90 \%$ on 6 -min walk test are independently associated with the presence of pulmonary hypertension and should prompt further evaluation for the presence of this disorder.

\section{ACKNOWLEDGEMENTS}

The authors would like to thank P. Smith-Cobb (Detroit Medical Center, Detroit, MI, USA) and J. Jannisse (Wayne State University School of Medicine, Detroit) for their invaluable assistance in completing the study. We would also like to thank J.A. Rowley (Wayne State University School of Medicine) for his assistance with editing and G.W. Hunninghake (University of Iowa, Iowa City, IA, USA) for critical review of the manuscript.

\section{REFERENCES}

1 Nunes H, Humbert M, Capron F, et al. Pulmonary hypertension associated with sarcoidosis: mechanisms, haemodynamics and prognosis. Thorax 2006; 61: 68-74.

2 Handa T, Nagai S, Miki S, et al. Incidence of pulmonary hypertension and its clinical relevance in patients with sarcoidosis. Chest 2006; 129: 1246-1252.

3 Baughman RP. Pulmonary hypertension associated with sarcoidosis. Arthritis Res Ther 2007; 9: Suppl. 2, S8.

4 Sulica R, Teirstein AS, Kakarla S, Nemani N, Behnegar A, Padilla ML. Distinctive clinical, radiographic, and functional characteristics of patients with sarcoidosis-related pulmonary hypertension. Chest 2005; 128: 1483-1489.
5 Preston IR, Klinger JR, Landzberg MJ, Houtchens J, Nelson D, Hill NS. Vasoresponsiveness of sarcoidosis-associated pulmonary hypertension. Chest 2001; 120: 866-872.

6 Baughman RP, Sparkman BK, Lower EE. Six-minute walk test and health status assessment in sarcoidosis. Chest 2007; 132: 207-213.

7 Shorr AF, Davies DB, Nathan SD. Predicting mortality in patients with sarcoidosis awaiting lung transplantation. Chest 2003; 124: 922-928.

8 Srigley JA, Pollanen MS. Sudden death with clinically undiagnosed pulmonary hypertension. J Clin Forensic Med 2005; 12: 264-267.

9 Barst RJ, McGoon M, Torbicki A, et al. Diagnosis and differential assessment of pulmonary arterial hypertension. J Am Coll Cardiol 2004; 43: Suppl. 5, 40S-47S.

10 ATS Committee on Proficiency Standards for Clinical Pulmonary Function Laboratories. ATS statement: guidelines for the six-minute walk test. Am J Respir Crit Care Med 2002; 166: 111-117.

11 Cahalin L, Pappagianopoulos P, Prevost S, Wain J, Ginns L. The relationship of the 6-min walk test to maximal oxygen consumption in transplant candidates with end-stage lung disease. Chest 1995; 106: 452-459.

12 Chetta A, Aiello M, Foresi A, et al. Relationship between outcome measures of six-minute walk test and baseline lung function in patients with interstitial lung disease. Sarcoidosis Vasc Diffuse Lung Dis 2001; 18: 170-175.

13 Eaton T, Young P, Milne D, Wells AU. Six-minute walk, maximal exercise tests: reproducibility in fibrotic interstitial pneumonia. Am J Respir Crit Care Med 2005; 171: 1150-1157.

14 Steele B. Timed walking tests of exercise capacity in chronic cardiopulmonary illness. J Cardiopulm Rehabil 1996; 16: 25-33.

15 Poulain M, Durand F, Palomba B, et al. 6-minute walk testing is more sensitive than maximal incremental cycle testing for detecting oxygen desaturation in patients with COPD. Chest 2003; 123: 401-407.

16 Cahalin LP, Mathier MA, Semigran MJ, Dec GW, DiSalvo TG. The six-minute walk test predicts peak oxygen uptake and survival in patients with advance heart failure. Chest 1996; 110: 325-332.

17 Hallstrand TS, Boitano LJ, Johnson WC, Spada CA, Hayes JG, Raghu G. The timed walk test as a measure of severity and survival in idiopathic pulmonary fibrosis. Eur Respir J 2005; 25: 96-103.

18 Miyamoto S, Nagaya N, Satoh T, et al. Clinical correlates and prognostic significance of six-minute walk test in patients with primary pulmonary hypertension: comparison with cardiopulmonary exercise testing. Am J Respir Crit Care Med 2000; 161: 487-492.

19 Kadikar A, Maurer J, Kesten S. The six-minute walk test: a guide to assessment for lung transplantation. J Heart Lung Transplant 1997; 16: 313-319.

20 Lederer DJ, Arcasoy SM, Wilt JS, D'Ovidio F, Sonett JR, Kawut SM. Six-minute-walk distance predicts waiting list survival in idiopathic pulmonary fibrosis. Am J Respir Crit Care Med 2006; 174: 659-664.

21 Paciocco G, Martinez FJ, Bossone E, Pielsticker E, Gillespie B, Rubenfire M. Oxygen desaturation on the six-minute walk test and mortality in untreated primary pulmonary hypertension. Eur Respir J 2001; 17: 647-652. 
22 Flaherty KR, Andrei A-C, Murray S, et al. Idiopathic pulmonary fibrosis: prognostic values of changes in physiology and six-minute-walk test. Am J Respir Crit Care Med 2006; 174: 803-809.

23 Lama VN, Flaherty KR, Toews GB, et al. Prognostic value of desaturation during a 6-minute walk test in idiopathic interstitial pneumonia. Am J Respir Crit Care Med 2003; 168: 1084-1090.

24 Statement on sarcoidosis. Joint Statement of the American Thoracic Society (ATS), the European Respiratory Society (ERS) and the World Association of Sarcoidosis and Other Granulomatous Disorders (WASOG) adopted by the ATS Board of Directors and by the ERS Executive Committee, February 1999. Am J Respir Crit Care Med 1999; 160: 736-755.

25 Standardization of Spirometry, 1994 Update. American Thoracic Society. Am J Respir Crit Care Med 1995; 152: 1107-1136.
26 American Thoracic Society. Single-breath carbon monoxide diffusing capacity (transfer factor). Recommendations for a standard technique-1995 update. Am J Respir Crit Care Med 1995; 152: 2185-2198.

27 Enright PL, Sherrill DL. Reference equations for the sixminute walk in healthy adults. Am J Respir Crit Care Med 1998; 158: 1384-1387.

28 McGoon M, Gutterman D, Steen V, et al. Screening, early detection, and diagnosis of pulmonary arterial hypertension: ACCP evidence-based clinical practice guidelines. Chest 2004; 126: Suppl. 1, 14S-34S.

29 Chemla D, Castelain V, Herve P, Lecarpentier Y, Brimioulle S. Haemodynamic evaluation of pulmonary hypertension. Eur Respir J 2002; 20: 1314-1331.

30 Shorr AF, Helman DL, Davies DB, Nathan SD. Pulmonary hypertension in advanced sarcoidosis: epidemiology and clinical characteristics. Eur Respir J 2005; 25: 783-788. 